\title{
DIPANGGIL UNTUK DIUTUS
}

\author{
Maria Hanie
}

\section{PENDAHULUAN}

Profil Yunus menarik untuk disimak, karena Yunus bisa dikatakan sebagai misionari pertama yang dicatat di dalam Perjanjian Lama. Di tengah pelayanannya sebagai nabi di kerajaan Israel Utara, Tuhan mengutus dia untuk pergi ke Niniwe dengan tugas yang jelas, yakni menyampaikan pesan Tuhan yang sangat penting. Dalam 2Raja-raja 14:25 disebutkan bahwa Yunus bin Amitai dari Gat-Hefer, menubuatkan bahwa Yerobeam II, raja Israel Utara (793-753 SM) akan mengambil kembali daerah milik Israel yang telah diduduki bangsa Aram, karena saat itu pemerintahan Aram melemah, di bawah Raja Benhadad II. Dan pemerintahan Israel Utara saat itu sangat kuat atau jaya di bawah Yerobeam II, meskipun raja itu tidak hidup takut akan Tuhan, dan memerintah sangat lama (2Raj 14:23-24).

\section{ANALISA BENTUK KITAB YUNUS}

\section{A. Latarbelakang Kitab Yunus}

Beberapa theolog modern mempersoalkan tentang penulis dan sifat historisitas kitab Yunus. Mereka beranggapan bahwa yang menulis kitab Yunus adalah seseorang yang hidup pada zaman sesudah pembuangan (kira-kira $350 \mathrm{SM}$ ) mengenai seorang nabi yang bernama Yunus yang hidup pada masa pemerintahan Yerobeam II (793-753 SM). Tujuan si penulis mengisahkan peristiwa ini adalah untuk menentang nasionalisme dan partikularisme Yahudi yang sempit, yang berkembang subur sesudah umat Israel kembali dari pembuangan. Para theolog itu menekankan universalisme, bahwa Allah Israel adalah juga Allah semua bangsa. Dengan kata lain, menurut mereka, kitab Yunus tidak historis, melainkan hanya dongeng belaka. Salah satu alasan keberatan para theolog itu adalah karena mujizat-mujizat yang diceritakan dalam kitab Yunus tidak masuk akal. J. Blommendaal menegaskan bahwa kitab ini tidak historis, karena di dalamnya terdapat peristiwa yang tidak pernah terjadi. ${ }^{1}$

Denis Green, mewakili theolog injili menyanggah pendapat yang meragukan mujizat-mujizat dalam kitab Yunus, dengan menuliskan: "Tetapi

1 J. Blommendaal, Pengantar Kepada Perjanjian Lama (Jakarta: BPK Gunung Mulia, 1979), 133-134. 
cukup jelas bahwa keberatan semacam ini merupakan buah pemikiran manusiawi saja, yang tidak memperhitungkan kuasa Tuhan untuk mengadakan mujizat." 2 Yang lebih akurat di atas semua pendapat theolog adalah pandangan Tuhan Yesus sendiri, yang dicatat dalam Injil Matius 12:39-42 dan Lukas 11:29-32. Ketika beberapa ahli Taurat dan orang Farisi meminta tanda dari Tuhan Yesus, dan Tuhan Yesus memakai tanda Yunus yang tiga hari tiga malam di perut ikan. Tuhan Yesus menegaskan bahwa peristiwa itu riil, juga pertobatan penduduk Niniwe adalah riil, bukan fiktif ataupun dongeng. Tentu kita tidak patut menyangkal kebenaran pernyataan Tuhan Yesus.

Nama Yunus artitnya merpati. Merpati biasanya dipakai sebagai lambang kesetiaan dan ketulusan. Tetapi memang tidak senantiasa arti nama seseorang sesuai dengan realita kehidupannya. Yang lebih menarik adalah karakter Yunus yang terekspresi jelas dalam kitab ini. Dalam meresponi pengutusan Tuhan, Yunus justru menunjukkan ketidak-setiaannya, dengan melarikan diri ke arah yang berlawanan dengan pengutusan Tuhan. Juga ketika Yunus toh akhirnya menyelesaikan tugasnya - setelah mendapat teguran keras dari Tuhan - justru marah kepada Tuhan karena kemurahanNya kepada orang berdosa, dengan membatalkan rencana penghukumanNya. Yunus memang sedang melayani sebagai seorang nabi. Di tengah pelayanannya Tuhan memanggil secara khusus untuk diutus untuk pergi memberitakan Firman Tuhan kepada orang-orang berdosa. Inilah sebenarnya tugas utama seorang hamba Tuhan.

Profil Yunus menjadi cerminan bagi semua hamba Tuhan, termasuk kita. Kiranya kita bisa selalu mawas diri dan menjaga hati dalam meresponi panggilan Tuhan kepada siapapun dan kemanapun kita diutus atau ditempatkan Tuhan untuk melayani Dia, serta memiliki sikap yang positif jika Tuhan menunjukkan rahmat-Nya kepada orang berdosa, termasuk kepada orang yang telah memberi goresan hitam dalam hidup umat Tuhan.

\section{B. Struktur Kitab Yunus}

Adapun struktur kitab Yunus mudah untuk diingat, yakni:

1. Panggilan Tuhan dan respon ketidaktaatan Yunus (ps. 1-2)

2. Panggilan Tuhan kedua kali dan respon ketaatan Yunus (ps. 3)

3. Sikap negatif Yunus atas penyataan rahmat Tuhan kepada orang berdosa, dan cara Tuhan memberi pelajaran khusus kepada hambaNya yang egois (ps. 4).

2 Denis Green, Pembimbing Pada Pengenalan Perjanjian Lama (Malang: Gandum Mas, 1984), 197. 


\section{EKSPOSISI KITAB YUNUS}

A. Panggilan Tuhan dan Respon Ketidaktaatan Yunus (Ps. 1-2)

\section{Panggilan Tuhan (1:1-2)}

\section{Pasal 1:1-2}

Terjemahan literal: Dan telah ada Firman TUHAN kepada Yunus, anak Amitai, demikian: Bangkitlah berjalanlah ke Niniwe, kota yang besar itu, Dan serukanlah atasnya, sebab telah naik kejahatan mereka di hadapanKU."

Ada tiga kata kerja dalam bentuk imperatif, yang dalam tata bahasa Ibrani adalah perintah yang mutlak harus ditaati tanpa syarat, yakni kata bangkitlah, berjalanlah, dan serukanlah. Kata bangkitlah dalam bahasa Ibrani קות memiliki arti: start, make a move, to go somewhere. ${ }^{3}$ Pengertian yang sama dipakai dalam Kejadian 13:17, yang dalam terjemahan lama LAI diartikan berangkatlah, dan dalam terjemahan baru LAI diartikan bersiaplah. Jadi di tengah pelayanan Yunus di Israel Utara, dia disuruh Tuhan untuk bersiap melaksanakan tugas yang sama sekali baru, yang pasti tidak pernah dia pikirkan sebelumnya.

Kata kedua adalah perintah berjalanlah, dalam bahasa Ibrani לִ

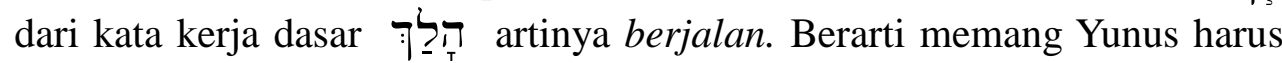
melangkah, taat kepada perintah baru dari Tuhan meskipun mungkin mengejutkannya, atau kurang menyenangkan dia yang sudah berada di tengah rutinitasnya sebagai nabi. Mengapa saya katakan bahwa perintah Tuhan itu kurang menyenangkan Yunus, karena kota Niniwe dan penduduknya bukanlah arah atau tempat pelayanan yang disukai Yunus, sebab Yunus mempunyai catatan khusus yang sangat negative terhadap penduduk Niniwe. Dan itu dibuktikan dengan Yunus pergi ke arah yang berlawanan dengan ke arah Niniwe.

Kota Niniwe dibangun oleh Nimrod (Kej 10:11) dan kemudian menjadi ibukota Asyur di bawah pemerintahan Sanherib (705-681 SM). Letak Niniwe di sebelah timur Sungai Tigris, kira-kira 550 mil timurlaut dari Samaria. Sedangkan di mata Tuhan, Niniwe dikatakan sebagai kota yang besar, bukan ukuran geografisnya yang besar, melainkan jumlah penduduknya yang tergolong besar pada zaman itu. Dan memang Tuhan tidak menginginkan orang faik mati dalam dosanya (Yeh 33:11).

3 Francis Brown, The Brown-Driver-Brigs- Hebrew and English Lexicon. Massachusetts: Hendrickson Publishers, 1979), 878. 
Kata ketiga adalah perintah serukanlah, dalam bahasa Ibrani וּק? dari kata dasar $\boldsymbol{N}_{\mathrm{T}}$ berseru, berteriak, memanggil. Perintah Tuhan kepada Yunus, bukan supaya Yunus berkata (Ibrani אָָּר), melainkan berseru atau berteriak. Kata dan biasanya diikuti oleh kata depan עַל yang harus diartikan against (melawan atau terhadap). ${ }^{4}$ Rupanya untuk berbicara kepada orang berdosa atau orang yang hidup dalam dosa, harus berteriak, artinya bukan saja volume suara yang harus keras, tetapi harus tegas, karena di hadapan Tuhan, kejahatan tidak boleh ditolerir. Dalam baris terakhir ayat 2 ditegaskan mengapa Yunus harus berteriak kepada penduduk Niniwe, karena kejahatan mereka telah naik di hadapan Tuhan. Pada prinsipnya, dosa adalah jahat di mata Tuhan. Istilah naik, tidak boleh dimengerti secara literal, melainkan harus difahami bahwa Tuhan menaruh perhatian yang sangat serius terhadap dosa penduduk Niniwe. Secara khusus kejahatan atau tindakan sadis penduduk Niniwe telah menjadi catatan sejarah bangsabangsa lain, termasuk Israel, sebagaimana ditulis oleh Sidlow Baxter:

Dalam politik orang Niniwe tidak boleh ada perasaan belas kasihan. Belas kasihan itu melemahkan balatentara; dalam praktek bahkan sebagian daripada balatentara itu harus ditinggalkan untuk menjaga daerah-daerah yang telah ditaklukkan. Sebab itu mereka itu main bunuh saja. Raja-raja Asyur gemar sekali mencatat pada tugu-tugu peringatan segala apa yang tampak di medan pertempuran. ${ }^{5}$

Kekejaman Asyur juga pernah dialami oleh Israel. Pada tahun 722 SM ketika Tuhan menyerahkan umat-Nya ke dalam tangan Asyur karena pemberontakan mereka kepada Tuhan dengan praktek penyembahan berhala. Dalam Yesaya 10:5 dicatat bahwa Asyur pernah menjadi "cambuk" Tuhan, namun kemudian Asyur memegahkan diri (ay. 15), dan berniat memunahkan bangsa-bangsa jajahannya, termasuk Israel (ay. 7).

\section{Ketidaktaatan Yunus (1:3)}

Pasal 1:3

Terjemahan literal: Tetapi Yunus telah bangkit untuk melarikan diri ke Tarsis dari hadapan TUHAN; Dan dia telah turun ke Yafo, Dan dia telah mendapatkan sebuah kapal sedang pergi ke Tarsis, Lalu dia telah menyerahkan ongkos (uang tiket) Dan dia telah turun ke dalamnya, untuk

\footnotetext{
Brown, The Brown-Driver-Brigs..., 896.

J. Sidlow Baxter, Menggali Isi Alkitab. Jilid II (Jakarta: BPK Gunung Mulia, 1981), 371
} 
pergi bersama mereka dari hadapan TUHAN.

Memang Yunus telah bangkit sebagaimana perintah Tuhan, tetapi arah tujuannya berlawanan dengan kehendak Tuhan. Kata melarikan diri dalam ayat ini dalam bentuk infinitif konstruk, dengan awalan ? yang artinya untuk atau dengan tujuan. Jadi, memang Yunus bangkit, tetapi dengan tujuan melarikan diri dari hadapan Tuhan, yakni dari tempat yang Tuhan tetapkan untuk hamba-Nya pergi melayani. Sebagai tulisan bentuk narasi, maka pengulangan frase atau kata menunjukkan ada penekanan pada frase atau kata yang diulang tersebut. Dalam ayat ini, keterangan dari hadapan Tuhan diulang di bagian akhir. Itu berarti, Yunus memang benarbenar ingin menghindar dari pengutusan Tuhan.

Kota Tarsis terletak di Spanyol, kurang lebih $4.000 \mathrm{~km}$ dari arah barat Israel, kota terjauh yang dapat dijangkau pada masa itu. Tarsis adalah pangkalan pertambangan. Dalam 1Raja-raja 22:49 dilaporkan bahwa Yosafat membuat kapal-kapal Tarsis untuk pergi ke Ofir mengambil emas. Tarsis sendiri kaya akan logam, misalnya perak dan diekspor ke luar negeri, seperti ke Tirus dan ke Yafo (bnd. Yer 10:9a). Yang penting bagi Yunus adalah jarak yang terjauh baginya untuk tidak pergi ke kota Niniwe. Yunus telah mengingkari tanggung jawabnya sebagai seorang nabi, yang seharusnya taat kemana saja dan kepada siapa saja Tuhan mengutusnya untuk menyampaikan Firman Tuhan, agar orang berdosa, bertobat, dan Tuhan selamatkan.

Proses pelarian Yunus diceritakan detail dalam ayat ini, yakni ia telah turun ke Yafo, mendapatkan kapal yang sedang transit sebentar, membeli tiket, lalu turun ke kapal untuk pergi bersama para penumpang di kapal itu, dari hadapan TUHAN. Langkah-langkahnya pelariannya nampak begitu mulus: punya uang cukup untuk membeli tiket, sesampai di pelabuhan sudah ada kapal bersandar untuk transit sebentar, menuju ke tempat yang dia maksudkan. Kata "sedang pergi" bahasa Ibraninya בגָר (bentuk partisip aktif, dalam arti "sedang"), berarti kapal tersebut sedang dalam perjalanan menuju ke Tarsis, dan singgah sebentar di Yafo, kota perdagangan dan pelabuhan kecil di pesisir barat Israel. Langkah-langkah yang mulus, belum tentu sebagai tanda restu Tuhan. Itulah pengalaman konkrit Yunus. Seolah-olah Tuhan lebih dulu mengizinkan Yunus lari dari hadapan-Nya, baru setelah itu Tuhan bertindak.

\section{B. Konsekwensi Ketidaktaatan Yunus (1:4 -2:10)}

\section{Pasal 1:4-5}

Terjemahan literal; Tetapi TUHAN sendiri telah melemparkan angin besar ke laut, Sehingga telah terjadi badai besar di laut; Maka para awak 
kapal itu telah menjadi takut, Lalu mereka telah ber-teriak2 masing2 kepada allahnya, Dan mereka telah melemparkan muatan2 yang dalam kapal itu ke laut, Untuk meringankan dari atas mereka; Tetapi Yunus telah turun ke bagian bawah kapal itu, Dan dia telah berbaring dan telah tidur lelap.

Kata "melemparkan" dalam bahasa Ibrani הִ̣ (hifil, perfek, 3,m,tg), dari kata טוּ (melemparkan). Maka jelas bahwa badai besar di laut yang menerpa kapal Yunus bukan sekedar fenomena alam, melainkan Tuhan-lah Subyeknya. Hal ini juga diperjelas dengan susunan kata pada baris pertama ayat $4 \mathrm{di}$ atas, di mana nama רִיהוֹזָה mendahului kata kerjanya, sehingga tepat diterjemah "TUHAN sendiri" atau "TUHAN-lah." Dicatat beberapa kali dalam Perjanjian Lama bahwa Tuhan memakai alam untuk melaksanakan maksud-maksudNya (Kel 14:21-22; Bil 11:31; 1Raj 17:1-6; dll). Dalam kitab Yunus sendiri, Allah memakai angin besar, ikan besar, pohon, matahari, angin timur, ulat, untuk mendidik hambaNya yang tidak taat dan egois.

Angin keras yang TUHAN lemparkan ke laut mengakibatkan terjadi badai besar di laut. Kata "badai" dari bahasa Ibrani סָעַ diterjemahkan dalam Septuaginta Kludwn, artinya "ombak atau gelombang besar" atau gelora, sehingga kapal bisa hancur berkeping-keping.

Maka wajar jika semua awak kapal berteriak kepada allah-allah mereka masing-masing, sesuai kepercayaan mereka tiap-tiap awak kapal yang tentunya berasal dari berbagai daerah dan suku. Mereka berseru-seru untuk mendapat pertolongan dari allah-allah mereka, bahkan mereka melemparkan semua benda muatan dalam kapal tersebut, agar kapal tidak terlalu berat dan bisa tenggelam. Bisa kita bayangkan betapa hiruk pikuknya di dalam tersebut, dan betapa serunya teriakan histeris dari seluruh awak kapal, ditambah dengan suara badai yang menggelegar memecahkan ombak yang meninggi, dan kapal pun pasti terombangombing luar biasa. Tetapi sangat ironis, bahwa Yunus bisa tidur lelap di

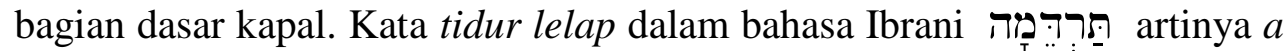
heavy/deep sleep, sampai mendengkur dan tidak mendengar apapun. Dalam buku The Bible Knowledge Commentary dijelaskan bahwa sikap Yunus ini adalah karena sikap apatis atau tidak peduli terhadap situasi sekitarnya. ${ }^{6}$

Melihat sikap Yunus, maka seorang kapten kapal merasa terheranheran, dan harus menegur Yunus dengan keras. Bagaimana mungkin sementara orang lain berteriak dengan sangat ketakutan di tengah ancaman maut, ada seseorang yang tidur lelap. Nampaknya sikap Yunus sangat menarik perhatian orang tersebut, karena memang sangat aneh. Orang

6 John F. Walvoord, The Bible Knowledge Commentary (Wheaton, Illinois: Victor Books, 1985), 1466. 
tersebut menegur Yunus dengan keras karena kesal, nampak pada kalimat: "Apa maksudmu sedang tidur lelap? Bangunlah, berteriaklah kepada Allahmu" (ay. 16b). Seorang hamba Tuhan yang melarikan diri dari panggilan Tuhan, mendatangkan murka Tuhan, dan dimana pun dia berada, tidak menjadi berkat, melainkan justru mendatangkan masalah atau malapetaka bagi orang-orang di sekitarnya. Ini hal yang prinsip. Dan yang sangat mengherankan ialah bahwa Yunus sebagai hamba Tuhan, bisa bersikap apatis terhadap penderitaan orang lain yang justru disebabkan oleh ulahnya.

Perintah awak kapal kepada Yunus: "Bangunlah berteriaklah kepada Allahmu” tentunya sangat menempelak Yunus sebagai seorang hamba Tuhan, yang seharusnya justru sebaliknya menasihati orang awam untuk berteriak kepada Tuhan untuk mendapat pertolongan ketika dalam krisis.

\section{Pasal 1:7}

Terjemahan literal; Lalu mereka telah berkata seorang kepada temannya: "Marilah kita menjatuhkan undian2, Sehingga kita akan tahu oleh karena siapa malapetaka ini bagi kita." Maka mereka telah menjatuhkan undian2, Dan sebuah batu undian telah jatuh atas Yunus.

Para awak kapal yang berasal dari berbagai daerah, setelah berseruseru kepada allah mereka dan tidak ada jawaban berupa pertolongan dari badai, akhirnya membuat undi untuk mengetahui siapa penyebab malapetaka itu. Dengan kata lain, praktek undi untuk mendapat suatu kepastian dari ketidaktahuan, sudah dipakai umum di luar Israel. Kata undian-undian dalam bahasa Ibrani גוֹרָרלוֹ artinya batu kecil/koral. Cara praktek undian adalah: sejumlah koral dikocok pada kantong kain, lalu dikocok, dan koral siapa yang jatuh menandakan itulah pelakunya. ${ }^{7}$

Tidak ada dosa yang tersembunyi di hadapan Tuhan. Dan suatu saat dosa yang disembunyikan pasti akan Tuhan bukakan (Ams 15:3). Tetapi sayang sekali jika, hamba Tuhan harus menunggu Tuhan bukakan dosanya di depan umum, apalagi di depan orang-orang yang tidak percaya Tuhan. Namun mungkin sewaktu-waktu perlu menurut Tuhan, jika hamba-Nya keras kepala, supaya menyadari dosanya, menyesalinya, dan bertobat tentunya. Kita tidak boleh keliru dalam hal undian: bukannya Tuhan ditentukan oleh undian, melainkan Tuhan bisa memakai undian untuk menyatakan kehendak-Nya, khususnya oleh karena belum tahu Firman

7 Earl S.Kalland dalam Laird R. Harris (ed), Theological Wordbook of the Old Testament. Vol. I (Chicago: Moody Press, 1980), 381. 
Tuhan dan situasi krisis.

Dengan menyaksikan bahwa batu undian yang jatuh adalah batunya Yunus, maka para awak kapal semakin takut lagi, sehingga semakin penasaran tentang pribadi Yunus, dan kemudian menginterogasi Yunus dengan beberapa pertanyaan, yang intinya (ay. 8). Profesi, suku, dan asal daerah seseorang sudah bisa menjadi bahan pertimbangan untuk mengambil kesimpulan penilaian terhadap orang tersebut. Akhirnya Yunus membukakan identitasnya.

Pasal 1:9

Terjemahan literal; Lalu dia (Yunus) telah berkata kepada mereka: "Seorang Ibrani-lah Aku, Dan kepada TUHAN Allah yang empunya langit aku telah takut, Yang telah membuat langit dan daratan.

Identitas diri yang Yunus bukakan adalah tentang daerah asalnya dan kepercayaannya. Tentang daerah asalnya, Yunus mengaku diri sebagai seorang Ibrani, dalam bahasa Ibrani עברִ adalah nama yang membedakan Israel dari bangsa-bangsa lain (Kej 14:13; 2Kor 11:22; Flp 3:5). Brown menjelaskan kata ini: used to distinguish Israel from beyond the Euphrates, from beyond the Jordan. ${ }^{8}$ Gerard von Gruningen menjelaskan kata ini: ‘ibri is used in the O.T. to refer to a specific ethnic group of people. ${ }^{9}$

Identitas kedua yang Yunus bukakan adalah tentang kepercayaannya atau statusnya, yakni: "kepada TUHAN Allah yang empunya langit aku telah takut, Yang telah membuat langit dan daratan." Pernyataan Yunus tidak sesuai dengan kenyataannya. Pernyataannya benar, tetapi praktek hidupnya sebaliknya. Pernyataannya theologis, tetapi praktisnya lebih jelek dari pada orang yang tidak mengenal Tuhan yang benar.

Pengakuan Yunus dengan sendirinya memperjelas para awak kapal siapa penyebab badai besar yang melanda mereka, dan hal itu membuat mereka bertambah takut.

\section{Pasal 1:10}

Terjemahan literal; Lalu orang2 itu telah menjadi takut dengan ketakutan yang besar, Dan mereka telah berkata kepadanya (Yunus): "Apa ini yang engkau telah lakukan?" Sebab orang2 itu telah tahu bahwa dari hadapan TUHAN dia sedang melarikan diri, karena ia (Yunus) telah menceritakan kepada mereka. 
Akhirnya Yunus membukakan pelanggarannya kepada TUHAN, walaupun dia seorang nabi TUHAN. Seorang hamba Tuhan, dipojokkan dulu, baru mengakui kesalahannya. Dan pengakuan Yunus justru membuat para awak kapal sangat takut, bukan takut kepada Yunus, melainkan kepada Tuhan. Pertanyaan mereka: Apa ini yang telah engkau lakukan? Maksudnya: bagaimana mungkin seorang yang katanya takut Tuhan, tetapi justru telah memberontak kepada Tuhan dengan ketidaktaatannya terhadap perintah atau penugasan Tuhan. Itulah sebabnya menimbulkan malapetaka besar. Inilah yang membuat semua awak kapal teramat sangat takut. Pasti mereka berpikir bahwa sebentar lagi akan binasa di laut oleh karena murka Tuhan-nya Yunus. Hal ini menunjukkan bahwa orang-orang di luar Tuhan, justru memiliki tingkat religius yang jauh lebih tinggi, dan lebih takut kepada allah.

Pertanyaan para awak kapal yang dicatat di ayat 11 menandakan bahwa mereka masih memiliki sikap etis yang tinggi, terlebih kepada orang yang menyatakan dirinya sebagai orang yang takut akan Tuhan. Pertanyaan mereka juga menandakan bahwa Yunus harus bertanggungjawab atas kesalahannya agar badai berhenti, karena laut semakin bergelora. Tuhan tidak akan berhenti sampai Yunus bertobat.

\section{Pasal 1:12}

Lalu dia (Yunus) telah berkata kepada mereka: "Angkatlah aku dan lemparkan aku ke laut, Maka laut akan reda atas kalian, Sebab aku tahu bahwa karena akulah badai besar ini atas kalian."

Permintaan Yunus ini tentu berdasarkan kesadarannya bahwa karena dialah badai besar itu terjadi sebagai wujud murka Allah, maka dia harus bersedia menerima akibatnya. Kata tahu dalam bahasa Ibraninya berbentuk partisip aktif, artinya Yunus saat sebenarnya tahu mengapa terjadi badai besar menerpa kapal tersebut. Hal ini diperjelas dengan pernyataan berikutnya: karena akulah badai besar ini atas kalian.

Yunus sadar bahwa dosa harus dibayar dengan kematian. Dan dengan kematiannya pula berarti penugasannya ke Niniwe tidak akan pernah terjadi. Tetapi Allah tak pernah gagal dalam melaksanakan programNya. Tuhan bisa memakai Yunus, tetapi juga bisa memakai orang lain.

Dalam ayat 13 dicatat bagaimana para awak kapal tidak segera melakukan permintaan Yunus, melainkan masih mencoba dan dengan usaha keras berdayung untuk kembali ke darat, namun mereka sama sekali tidak mampu, sebab laut terus bergelora, dan badai semakin besar atas mereka.

Karena itu mereka kemudian berseru kepada karena ternyata allah-allah mereka tidak bisa mendengar doa mereka dan tidak mampu menolong mereka, oleh karena allah mereka sebenarnya tidak 
ada. Hanya ada satu Allah, yang memperkenalkan dirinya dengan nama Pִ: Pencipta alam semesta.

Pasal 1:14

Terjemahan literal; Kemudian mereka telah berseru kepada TUHAN: "Kami mohon ya TUHAN, janganlah kami akan hancur karena jiwa orang ini, Dan janganlah Engkau serahkan atas kami darah tak bersalah; Sebab Engkaulah TUHAN, Seperti yang Engkau telah anggap baik, Engkau telah lakukan."

Kalimat di atas diucapkan oleh para awak kapal sebelum mereka melemparkan Yunus ke laut. Maksud kalimat janganlah kami akan hancur karena jiwa orang ini, adalah karena ketidak taatan Yunus atas pengutusan Tuhan sehingga para awak kapal akan hancur jika kapal pecah. Istilah

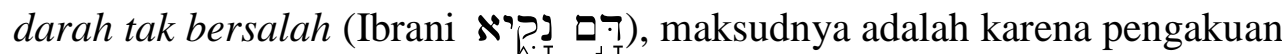
Yunus sebagai orang yang takut akan TUHAN. Mereka tidak ingin menanggung resiko berupa malapetaka yang lebih berat lagi jika mereka harus melemparkan Yunus ke laut yang bergelora sebagaimana permintaan Yunus.

Bagian kedua ayat ini dapat dikatakan sebagai pernyataan iman mereka kepada Tuhannya Yunus: "Sebab Engkaulah TUHAN, seperti yang Engkau telah anggap baik, Engkau telah lakukan." Pengakuan ini berdasarkan pengalaman nyata saat itu, bagaimana kehadiran dan kuasa Allah-nya Yunus yang dahsyat itu sungguh mereka alami, bukan seperti allah-allah yang mereka sembah atau percayai. Para awak kapal juga berusaha kembali ke darat untuk menyelamatkan kapal, tetapi selama ada Yunus di dalamnya, usaha mereka sia-sia, karena obyek Tuhan adalah Yunus. Karena itu mereka mengatakan: seperti yang Engkau telah anggap baik, Engkau telah lakukan," bukan yang menurut manusia baik.

Ayat 15 mencatat bahwa setelah mereka berseru kepada TUHAN, kemudian mereka telah mengangkat Yunus dan melemparkan dia ke laut," kemudian laut reda. Kata reda dalam bahasa Ibrani עמפר dalam konteks ayat ini artinya stabd stukkm stop, cease moving. ${ }^{10}$ Kenyataan itu membuat mereka mempunyai sikap yang baru.

Pasal 1:16

Terjemahan literal; Kemudian orang-orang itu telah menjadi takut dengan ketakutan yang besar kepada Tuhan; Lalu mereka telah mempersembahkan kurban untuk TUHAN, Dan mereka telah menazarkan nazar-nazar. 
Kalau di ayat 5 dan 10 dicatat para awak takut karena badai besar dan mereka berseru-seru kepada allah-allah mereka. Tetapi di ayat 16 ini mereka takut dengan ketakutan yang besar kepada Tuhan, karena melihat dan mengalami kehadiran dan kedahsyatan-Nya. Dan ketakutan mereka dinyatakan dengan mempersembahkan kurban untuk Tuhan disertai nazarnazar yang mereka ucapkan. Persembahan kurban yang mereka lakukan juga sebagai wujud ucapan syukur kepada Tuhan yang telah menolong menyalamatkan mereka dari ancaman maut. Nazar memang sudah menjadi kebiasaan masyarakat umum waktu itu ketika dalam krisis, sebagai janji kepada Tuhan karena telah atau menanti pertolongan Tuhan.

Kata nazar, Ibrani נִרדרים artinya vow, motive offering. Jadi untuk mengucapkan nazar itulah mereka mempersembahkan kurban. Itu berarti nazar mereka ditandai atau diperteguh dengan kurban atau penumpahan darah kurban. Jadi bukan sekedar lip service yang mudah diabaikan.

Menurut C.F. Keil, nazar yang mereka nazarkan kemungkinan adalah bahwa mereka akan melanjutkan persembahan kurban setelah mereka tiba di daratan di tempat yang mereka tuju. ${ }^{11}$ Bandingkan pengalaman Naaman yang dicatat dalam 2Raja-raja 5:17. Dengan mengucapkan nazar kepada Tuhan, berarti sikap percaya mereka kepada Tuhan tidak hanya sesudah keluar dari krisis, melainkan mereka ingat terusmenerus.

\section{Pasal 1:17 - 2:10}

Kembali kepada Yunus. Setelah Yunus dilemparkan ke laut yang bergelora, nampaknya dia sampai ke dasar laut (2:3), dan sudah sampai di dasar laut (2:5-6) dan di sana kepalanya dililit oleh lumut laut, saat seperti itu ia sadar bahwa tidak mungkin lagi dapat menyelamatkan diri, dan tidak seorang pun yang dapat menolongnya. Pada saat Yunus merasa "baut-

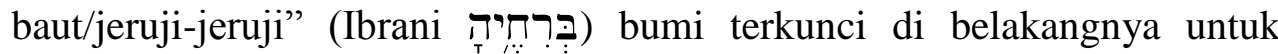
selamanya, Tuhan segera bertindak dengan memerintahkan seekor ikan besar (belum tentu ikan Paus) untuk menelan Yunus hidup-hidup: "namun Engkau telah mengangkat hidupku dari lubang, ya Tuhan, Allahku” (2:6b).

Tidak perlu didiskusikan bagaimana posisi dan kondisi Yunus ketika di dalam perut ikan. Tetapi yang terpenting adalah bahwa Tuhan membawa Yunus ke dalam perut ikan, di sana dia berkesempatan berdoa (2:1). Di sana Tuhan memberi kesempatan berharga untuk Yunus merenungkan segala perbuatannya sebagai seorang hamba Tuhan yang telah melarikan diri dari panggilan Tuhan, dengan segala konsekwensinya. Bila memperhatikan

11 Carl F. Keil, \& F. Delitzsch, Commentary on the Old Testament. Vol. X (Grand Rapids, Michigan: Wm. B. Eerdmans Publishing Company, 1989), 397. 
rumusan doanya, nampaknya banyak diwarnai doa dari kitab Mazmur. Kemungkinan Yunus sudah menghafal lagu-lagu rohani atau mazmurmazmur.

Setelah Yunus sampai pada sikap yang baru, hendak mempersembahkan ucapan syukur dengan suaranya (puji-pujian), dan hendak membayar apa yang dia telah nazarkan (mungkin kesediaannya ke Niniwe), maka Tuhan berfirman kepada ikan besar itu agar memuntahkan Yunus ke darat (pantai barat Israel). Sesungguhnya jika Tuhan berkenan mengutus Yunus untuk menyampaikan firman-Nya kepada penduduk Niniwe, itu adalah satu penghargaan yang luar biasa, dan seharusnya diterima dengan ucapan syukur, serta menaatinya. Setelah Yunus memiliki komitmen baru, maka Tuhan membawa hamba-Nya ke tempat yang Dia maksudkan.

\section{PANGGILAN TUHAN KEDUA KALI DAN RESPON KETAATAN YUNUS (Ps. 3)}

Tuhan tidak akan membuang hamba-Nya, asalkan bersedia bertobat, dan kembali pada panggilan dan rencana-Nya.

\section{A. Pengutusan Kedua Kali}

\section{Pasal 3:1-2}

Terjemahan literal; Lalu Firman Tuhan telah ada kepada Yunus kedua kalinya demikian: "Bangunlah berjalankah ke Niniwe kota yang besar itu; Dan serukan atasnya seruan ini yang Aku terus-menerus firmankan kepadamu."

Tuhan konsisten dengan keputusan-Nya agar Yunus menyampaikan Firman-Nya kepada Niniwe. Perhatikan bahwa perintah-Nya sama seperti perintah awal. Tetapi dalam pengutusan kedua ini ada tambahan: seruan ini yang Aku terus-menerus firmankan kepadamu." Memang Firman Tuhan yang Dia terus-menerus firmankan kepada Yunus tidak dituliskan detail dalam kitab ini sebagaimana kitab-kitab para nabi lain, tetapi inti pemberitaan Yunus dicatat dalam ayat 4b (LAI: ay.3b). Jadi, bukan menurut apa yang dalam hati dan pikiran Yunus.

\section{B. Respon Yunus}

\section{Pasal 3:3-4}


Terjemahan literal; Dan Yunus telah bangun, Lalu dia telah berjalan/pergi ke Niniwe seperti Firman Tuhan; Sedangkan Niniwe telah menjadi kota yang sesar bagi Allah, Satu perjalanan 3 hari Kemudian Yunus telah mulai untuk masuk dalam kota, Perjalanan 1 hari; Lalu dia telah berseru dan berkata:

Terhadap pengutusan kedua ini, Yunus taat. Dia pergi ke Niniwe seperti Firman Tuhan. Yunus tidak berani lagi melarikan diri dari panggilan Tuhan. Karena telalu mahal harga yang harus dia bayar akibat ketidaktaatannya.

Penjelasan "satu perjalanan 3 hari," maksudnya adalah lamanya Yunus melayani di Niniwe hingga pemberitaannya bisa mencapai seluruh penduduk Niniwe, dari lapisan bawah maupun para pembesar. Selama 3 hari itu tentunya Yunus bukan hanya berjalan terus tanpa berhenti, melainkan dia berkhotbah dari satu tempat ke tempat yang lain, mencari tempat-tempat yang strategis, di keramaian banyak orang (pasar, kuil, di jalan, dll), sehingga pemberitaannya efektif.

Penjelasan tentang "perjalanan 1 hari," maksudnya adalah pada saat Yunus memasuki kota Niniwe, tentu perlu waktu untuk melihat-lihat kota itu, dan memikirkan bagaimana cara pemberitaannya yang efektif. C.F. Keil menjelaskan hal ini demikian: "that he did not preach directly he entered the city, but only after he had commenced a day's journey, that is to say, had gone some distance into the city."12

Inti pemberitaan Yunus adalah bahwa Niniwe sampai 40 hari sedang dihancurkan, maksudnya ialah Niniwe sedang menuju kehancuran jika tidak bertobat dari segala kejahatan mereka, tentu terhitung sejak Yunus menyampaikan pesan Tuhan. Tentunya Yunus harus menjelaskan mengapa hal itu akan terjadi, dan bahwa 40 hari adalah wujud kemurahan Tuhan yang memberi kesempatan mereka untuk bertobat. Sebab sesungguhnya, maksud akal jika Tuhan menyatakan murkaNya kepada mereka.

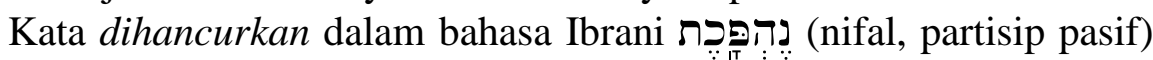
dari kata kerja dasar ${ }_{T}$ artinya be overturned (dijatuhkan, ditulingkan, dijungkirbalikkan), atau overthrown (dirubah, digulingkan). Kata yang sama juga dikenakan bagi kehancuran kota Sodom dan Gomora. LAI menerjemahkan kata ini dalam Kejadian 20:25 menunggang-balikkan tanpa tersisa yang bisa dibangun kembali.

C. Dampak Pemberitaan Yunus di Niniwe

Pasal 3:5

12 Keil, Commentary on the Old ... X, 406 
Terjemahan literal; Sehingga orang-orang Niniwe telah percaya di dalam Allah; Dan mereka telah menyerukan puasa dan mengenakan karung/goni, Dari yang besar sampai yang kecil dari mereka.

Akibat pemberitaan Yunus adalah orang-orang Niniwe telah percaya di dalam Allah. Kata percaya dari bahasa Ibrani אבֵ support. Dalam ayat ini, kata tersebut dalam konjugasi Hifil, yang lebih tepat diterjemahkan trust atau believe, yang jika diikuti oleh preposisi ב berarti trust in atu believe in. ${ }^{13}$ Jack B Scott menjelaskan kata khususnya dalam konjugasi Hifil demikian:

In the Hiphil (causative), it basically means "to cause to be certain, sure" or "to be certain about", "to be assured". In this sence the word in the Hiphil conjugation is the biblical word for "to believe" and shows that biblical faith is a assurance, a certainty, in contrast with modern concepts of faith as something possible, hopefully true, but not certain. ${ }^{14}$

Tindakan berpuasa dan mengenakan kain goni, menurut tradisi adalah sebagai tanda dukacita, penyesalan akan dosa, keprihatinan, dan sikap merendahkan diri di hadapan Allah. Kata goni dalam ayat ini, dalam

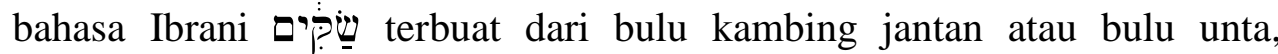
berwarna gelap, biasanya dikenakan pada upacara perkabungan. Contoh lain, ketika Yakub mendengar berita bahwa Yusuf telah diterkam binatang buas (Kej 37:34). ${ }^{15}$

Pasal 3:6

Terjemahan literal; Dan perkataan itu telah sampai kepada raja Niniwe, Lalu dia telah bangun dari tahtanya, Dan dia telah melepaskan jubahnya dari atasnya (dari badannya) Dan dia telah berselubung goni, Lalu dia telah duduk di atas debu.

Yunus tidak berkhotbah di depan raja Niniwe. Tetapi berita yang disampaikan Yunus sangat menghebohkan seluruh rakyat yang telah mendengar khotbahnya, betapa tidak, karena beritanya tentang penghukuman Allah, bahwa 40 hari lagi Niniwe akan dihancurkan. Tentulah berita dari mulut ke mulut, akhirnya sampai juga kepada raja Niniwe. Dan yang menarik dalam catatan ini adalah bahwa raja Niniwe tidak tersinggung lalu marah, melainkan bersikap sangat positif. Dirinya sendiri bertindak secara konkrit, dengan turun dari tahtanya, menanggalkan 
jubah kebesarannya, dan duduk di atas abu. Ini wujud penyesalan dan merendahkan diri di hadapan Allah. Di samping itu, dia juga mengeluarkan dekrit melalui para menterinya, agar seluruh rakyatnya sungguh meresponi pemberitaan Yunus, bahkan harus mengenakan goni pada ternak, dan tidak mengizinkan memberi makanan kepada ternak. Nampaknya overacting. Tetapi, tindakan ini wujud respons yang sangat positif terhadap Firman Tuhan yang disampaikan Yunus. Tentang dekrit raja Niniwe ini, C.F. Keil berpendapat demikian: It was a manifestation of the thought, that just as the animals which live with man are drawn into fellowship with his sin, so their sufferings might also help to appease the wrath of God. ${ }^{16}$

Pasal 3:10

Terjemahan literal; Maka Allah telah melihat perbuatan-perbuatan mereka, Karena mereka telah kembali dari jalan-jalan mereka yang jahat. Sehingga Allah telah menyesal atas malapetaka yang Dia telah katakan, Yang Ia telah firmankan untuk Ia lakukan bagi mereka, tetapi Ia tidak lakukan.

Perbuatan-perbuatan mereka yang dimaksudkan adalah sikap merendahkan diri dengan penuh penyesalan, yang diwujudkan dengan mengenakan kain goni dan berpuasa. Sikap merendahkan diri dan penyesalan ini menimbulkan respon Tuhan. Sehingga Tuhan membatalkan penghukuman yang Dia telah putuskan. Istilah Allah menyesal, נָָד tidak boleh difahami secara manusiawi, bahwa keputusan Tuhan mudah diubah oleh sikap manusia. Allah menyesal di sini adalah penghukuman yang Dia batalkan oleh karena pertobatan manusia. Marvin R. Wilson menjelaskan tentang kata נָָָד demikian: "Thus the OT states that God 'repented' of the judgments or 'evil' which he had planned to carry out (1Chr 21:15; Jer. 18:8; 26:3,19; Amos 7:3,6; Jon. 3:10). ${ }^{17}$ Di sini menunjukkan sifat Allah yang Maha Pengasih, Murah hati, dan penuh Pengampunan, serta Adil adanya. Keadilan-Nya Nampak ketika Tuhan menghukum orang berdosa, dan memberi anugerah pengampunan kepada orang yang bertobat. Jika Tuhan tetap menghukum orang yang bertobat, Dia bukan Tuhan yang adil.

Memang pada tahun 612 SM kota Niniwe dihancurkan, karena generasi-generasi berikutnya yang tidak lagi mengenal revival kurang lebih 200 tahun silam, kembali kepada kejahatan semula, sehingga tongkat pukulan dari Tuhan, Raja atas segala raja, harus dijatuhkan juga. 


\section{SIKAP NEGATIF YUNUS ATAS PENYATAAN RAHMAT TUHAN KEPADA ORANG BERDOSA, DAN CARA TUHAN MEMBERI PELAJARAN KHUSUS KEPADA HAMBANYA YANG EGOIS (Ps.4)}

Sesudah pemberitaannya, Yunus ke luar dari kota Niniwe, tidak langsung pulang ke Israel, melainkan tinggal di sebelah timur kota itu, dan membuat pondok untuk menyaksikan penghukuman Tuhan atas kota itu (ay. 5). Tentu dia mengambil jarak yang cukup sehingga dia tidak terkena malapetaka yang akan menimpa kota Niniwe. Ternyata sampai 40 hari sejak pemberitaannya, penghukuman Tuhan tidak kunjung terjadi. Dan hal ini menimbulkan respon negative Yunus sebagaimana dicatat dalam ayat 1-4.

\section{A. Sikap Negatif Yunus Atas Penyataan Rahmat Tuhan Kepada Niniwe}

\section{Pasal 4:1-5}

Terjemahan literal; Namun hal itu tidak menyenangkan kepada Yunus - kejahatan yang besar; Dan hal itu membuat marah baginya. Lalu dia telah berdoa kepada TUHAN demikian: Nah TUHAN, tidakkah hal ini perkataanku saat aku masih berada di negeri itu, Oleh sebab itulah aku telah sebelumnya untuk melarikan diri ke Tarsis; Karena aku telah tahu bahwa Engkau adalah Allah yang:

1. sangat ramah dan sangat merasa kasihan,

2. lambat murka dan banyak kasih setia,

3. dan menyesal atas malapetaka.

Maka sekarang ya TUHAN, ambillah nyawaku dari padaku, Sebab lebih baik kematianku dari pada hidupku Tetapi TUHAN telah berkata:"Menjadi baikkah kemarahan bagimu?"

Tindakan pengampunan Tuhan atas penduduk Niniwe yang bertobat, justru mendapat respon yang sangat negatif dari Yunus. Menurut Yunus, tindakan pengampunan Tuhan itu adalah satu kejahatan atau kesalahan yang besar, dan membuat Yunus marah. Istilah kejahatan, dari bahasa Ibrani רעַע artinya tidak menyenangkan hati, menyakitkan hati, menjengkelkan, mengesalkan.

Kekesalannya diungkapkan dalam bentuk doa yang penuh kemarahan kepada Tuhan. Dari ungkapannya tersebut, nampaknya Yunus sudah pernah menjawab pengutusan Tuhan dengan penolakan, dan itu sebabnya dia pergi ke arah yang berlawanan. Alasan penolakan terhadap pengutusan Tuhan karena pengenalannya tentang sifat-sifat hakiki Tuhan. Namun pengenalan Yunus sebagai seorang nabi, tentang sifat-sifat hakiki Tuhan kepada orang berdosa, tidak membuatnya bersukacita dan memberi dorongan keras untuk menaati pengutusan Tuhan ke penduduk Niniwe yang 
nyaris binasa dalam dosa-dosa mereka, tetapi justru membuatnya marah besar, sampai-sampai ingin mati saja. Karena menurut konsep Yunus orang berdosa patut menerima penghukuman, dan bukan pengampunan. Dan penduduk Niniwe yang sangat jahat itu, patut dihukum keras. Konsep yang benar benar tentang sifat-sifat Tuhan, tetapi berlawanan dengan kehendak Yunus jika sifat Tuhan itu dikenakan bagi Niniwe. Dengan kata lain, menurut Yunus: penduduk Niniwe tidak layak menerima belas kasihan Tuhan. Yunus sebagai seorang nabi, tugas utamanya adalah menyampaikan Firman Tuhan kepada orang berdosa agar bertobat dan menerima pengampunan Tuhan. Tetapi tidak demikian halnya bagi Yunus terhadap penduduk Niniwe. Di sini jelas menunjukkan sifat egosentris Yunus. ${ }^{18}$

Alasan kemarahan Yunus karena kemurahan Tuhan sebenarnya berdasarkan nasionalismenya yang salah, yaitu jika Tuhan batal menghukum Niniwe, maka Asyur akan tetap merupakan kekuatan adidaya di kawasan Timur Tengah waktu itu. Dan hal ini merupakan ancaman besar bagi bangsa-bangsa di sekitarnya, termasuk Israel. Yunus lupa bahwa sejak nenek moyangnya Israel dipanggil Tuhan untuk menjadi berkat bagi bangsa-bangsa lain (Kej 12:2-3). Seharusnya dia berpikir bahwa jika Niniwe (Asyur) bertobat, mereka tidak akan lagi melakukan kejahatan dan kekejaman terhadap bangsa-bangsa lain, termasuk Israel. Sikap Yunus ini berlawanan dengan sikap Musa yang meminta Tuhan menghapus namanya dalam kitab di surga jika Tuhan tidak mau mengampuni umat Israel (Kel 32:32).

Terhadap sikap Yunus itu, Tuhan mengajukan pertanyaan: "Menjadi baikkah kemarahan bagimu?" Maksudnya adalah: Apakah dengan Yunus marah itu mendatangkan kebaikan bagi Yunus. Theo Laetsch mengembangkan pertanyaan Tuhan demikian:

You who have just experienced My grace, when in disregard of your disobedience I delivered you in so miraculous a manner from welldeserved death, are you angry because this same grace is ready to help and save not only you, not the Jews alone, but likewise the Gentile nations? Is it proper, right, good for you so to do? ${ }^{19}$

Ternyata Yunus tidak sanggup menjawab pertanyaan Tuhan, sampai kemudian Tuhan mendidiknya dengan memberi pelajaran baru, untuk menyatakan otoritasNya di depan hamba Tuhan yang sangat mementingkan dirinya sendiri. Yunus tidak mengingat dirinya sendiri, jika bukan karena kemurahan dan belas kasihan Tuhan, dia sudah mati di dasar lautan setelah dia dilemparkan ke laut. Orang yang egois memang tidak melihat dirinya

\footnotetext{
18 Walvoord, The Bible Knowledge..., 1470.

19 Theo Laetsch, The Minor Prophets (Saint Louis, Missouri: Concordia Publishing House, 1956), 240.
} 
sendiri yang penuh kelemahan, dan selalu melihat kelemahan orang lain yang dianggap tidak patut menerima kemurahan Tuhan.

\section{B. Pendidikan Tuhan Kepada Yunus}

Cara Tuhan memberi pendidikan bagi Yunus sangat unik. Pada waktu yang singkat Tuhan menumbuhkan sejenis pohon yang menjalar ke atas, dengan daunnya yang lebar, sehingga cepat menjadi rimbun, dan bisa menjadi tempat bernaung terhadap terik matahari. Mengenai jenis pohon ini, Denis Green mejelaskan: "sudah dibuktikan bahwa di daerah tropis pohon jarak dapat tumbuh paling sedikit $30 \mathrm{~cm}$ tiap hari, maka memerlukan waktu paling lama 3 hari sampai cukup tinggi untuk menaungi kepala orang yang duduk di bawahnya."20 Pohon itu Tuhan tumbuhkan untuk menghibur Yunus, hamba-Nya yang sedang kesal, dan ingin mati, sehingga ia bersukacita atas pohon itu, dengan sukacita yang besar (ay. 6).

Pada saat Yunus menikmati naungan pohon tersebut, saat itulah Tuhan memberi pendidikan yang sangat penting, yang menyatakan otoritasNya atas segala sesuatu di ala mini, termasuk atas manusia. Tuhan menentukan atau memakai seekor ulat menggerek (mungkin akar) pohon tersebut menjelang fajar, sehingga pada waktu yang sangat singkat pohon itu layu, dan ketika Yunus hendak bernaung lagi dari terik matahari, tidak ada lagi tempat bernaung (ay. 7). Ditambah lagi, Tuhan menentukan angin timur yang panas dan pengap, dan dengan sengatan matahari, maka membuat Yunus lemas. Saat itulah Yunus sekali lagi minta mati kepada Tuhan, karena kemarahannya kepada Tuhan (ay. 8).

\section{Pasal 4:10-11}

Terjemahan literal; Lalu TUHAN telah berkata: Engkau sendiri telah merasa kasihan atas pohon itu, Yang engkau tidak kerja keras atasnya dan tidak membuatnya tumbuh, Yang tumbuh satu malam dan telah mati dalam satu malam. Dan bagaimana Aku sendiri tidak akan merasa belas kasihan atas Niniwe, Kota yang besar itu, Yang di dalamnya ada lebih dari 120.000 orang, Yang tidak faham antara tangan kanan dari tangan kirinya, Dan ternaknya banyak.

Kalimat di atas sangat tajam, dan menempelak Yunus sebagai seorang hamba Tuhan, yang seharusnya prihatin terhadap orang-orang berdosa. Dalam kalimat di atas, Tuhan membawa Yunus untuk memahami mana yang lebih berharga: manusia ataukah pohon. Yunus lebih sayang 
kepada pohon itu dari pada kepada penduduk Niniwe. Sedangkan kepada pohon itu, tidak ada andil Yunus sama sekali untuk menumbuhkannya. Tuhan mau mengajarkan kepada Yunus bahwa manusia jauh lebih berharga dari pada ciptaan lain di alam ini. Juga Yunus tidak patut untuk marah kepada Tuhan, karena semua berada di bawah otoritas-Nya.

Ayat di atas memberi penekanan bahwa manusia jauh lebih berharga dari apa pun di dunia ini, karena Tuhan telah menciptakan sebagai gambarNya sendiri (Kej 1:26-27), dan Tuhan tidak menginginkan kematian manusia di dalam dosanya, melainkan pertobatannya dan menerima anugerah keselamatan dari Tuhan (Yeh 33:11). Tuhan akan menuntut pertanggungjawaban dari semua hamba Tuhan membiarkan orang berdosa mati di dalam dosanya karena hamba Tuhan tidak mau memberitakan Firman Tuhan kepada orang itu (Yeh 3:18)

\section{KESIMPULAN DAN REFLEKSI BAGI HAMBA TUHAN}

\section{A. Kesimpulan}

Yunus dipanggil Tuhan di tengah rutinitas pelayanannya di Israel Utara untuk diutus ke Niniwe, melaksanakan program baru Tuhan, yakni menyampaikan berita penghukuman kepada penduduk Niniwe yang terkenal kejahatannya, yang juga dialami oleh Israel. Keputusan Tuhan untuk menghukum Niniwe sudah bulat. Namun sebelum Tuhan menjatuhkan penghukumanNya, terlebih dulu Tuhan memberi waktu anugerah selama 40 hari, karena pada prinsipnya Tuhan tidak menginginkan kematian orang dalam dosanya, melainkan pertobatannya, supaya mendapat pengampunan Tuhan. Untuk itulah Tuhan mengutus Yunus ke sana.

Pengalaman Yunus terhadap kejahatan Niniwe, dan pengenalan Yunus akan sifat-sifat Tuhan-nya, membuat Yunus melarikan diri dari pengutusan Tuhan. Karena menurut Yunus, Niniwe tidak patut mendengar Firman Tuhan dan menerima pengampunan Tuhan, melainkan sebaliknya patut menerima penghukuman Tuhan.

Program Tuhan demi keselamatan manusia berdosa tidak bisa dibatalkan oleh ketidaksetiaan hamba Tuhan. Adalah anugerah Tuhan semata-mata jika Tuhan melayakkan Yunus untuk melayani Tuhan sesuai program Tuhan. Termasuk jika Tuhan membawanya kembali kepada pusat kehendakNya, walaupun dengan cara yang dahsyat.

Pada prinsipnya: upah dosa adalah maut. Tetapi Tuhan itu penuh belas kasihan dan murah hati. Sebelum Tuhan menfonis maut bagi orang berdosa, terlebih dulu penting orang berdosa itu mendengarkan Firman Tuhan. Untuk itu, Tuhan mengutus nabi-Nya. Maka tugas seorang nabi 
adalah penyambung lidah Tuhan kepada orang berdosa.

Dosa sebesar atau seberat apapun, Tuhan sanggup mengampuni, asal dengan penuh kesadaran dan kesungguhan merendahkan diri dan bertobat kepada Tuhan. Namun bagi hamba Tuhan harus tetap menjaga hati, agar tidak justru jengkel ataupun marah karena Tuhan membatalkan keputusan penghukumannya, karena bagi Tuhan: manusia lebih berharga dari apapun di dunia ini.

\section{B. Refleksi Bagi Hamba Tuhan}

1. Biasanya hamba Tuhan merasa nyaman berada di tengah kemapanan pelayanannya. Apalagi jika hamba Tuhan sudah memiliki segala fasilitas lengkap, juga kehangatan persekutuan di dalam jemaat yang dia layani. Hamba Tuhan seperti ini, akan mengalami kesulitan, atau keberatan hati, jika sewaktu-waktu dan tiba-tiba Tuhan memanggil dan mengutusnya ke tempat yang lain, yang tak pernah dia pikirkan sebelumnya.

2. Sebelum Tuhan menjatuhkan penghukuman, terlebih dulu Tuhan memanggil dan mengutus seorang hambaNya untuk menyampaikan undangan Tuhan untuk bertobat. Maka hamba Tuhan pun mutlak harus menaati tugas Ilahi tersebut. Karena itu adalah tugas utama seorang hamba Tuhan.

3. Kebencian dan sikap apriori kepada seseorang atau satu etnis tertentu akan menjadi penghalang seorang hamba Tuhan taat pada panggilan dan pengutusan Tuhan. Dan bagimana sikap hati kita jika Tuhan mengampuni orang berdosa yang kita layani?

4. Seorang hamba Tuhan yang melarikan diri dari panggilan Tuhan, akan mendatangkan murka Tuhan, dan dimana pun dia berada, tidak menjadi berkat, melainkan justru mendatangkan masalah atau malapetaka bagi orang-orang di sekitarnya.

5. Tidak ada dosa yang tersembunyi di hadapan Tuhan. Dan suatu saat dosa yang disembunyikan pasti akan Tuhan bukakan (Amsal 15:3). Tetapi sayang sekali jika hamba Tuhan harus menunggu Tuhan bukakan dosanya di depan umum, apalagi di depan orang-orang yang tidak percaya Tuhan. Namun mungkin sewaktu-waktu perlu menurut 
Tuhan, jika hamba-Nya keras kepala, supaya menyadari dosanya, menyesalinya, dan bertobat tentunya.

6. Seorang hamba Tuhan, apalagi sudah studi theologia pasti sudah memiliki banyak rumusan theology. Tetapi hal itu seharusnya sejalan (seperti rel kereta api) dengan praktek hidupnya.

7. Sesungguhnya jika Tuhan berkenan mengutus seseorang untuk menyampaikan firman-Nya kepada orang berdosa, itu adalah satu penghargaan yang luar biasa, dan seharusnya diterima dengan ucapan syukur, serta menaatinya, tanpa mempertimbangkan sesuai hikmatnya.

8. Ada banyak cara Tuhan mendidik hamba Tuhan agar tidak egois. Tuhan mau agar hamba-Nya memiliki hati yang berbelas kasihan kepada orang berdosa, serta memahami bahwa manusia lebih berharga dari apapun di dunia ini. Jangan sampai hamba Tuhan lebih menyayangi suatu materi apapun, lebih dari mengasihi jiwa-jiwa yang nyaris binasa. Sikap Musa menjadi contoh bagi semua hamba Tuhan. Musa memohon kepada Tuhan agar namanya dihapus saja dari Kitab Kehidupan di surga, daripada Tuhan menghukum umatNya (Kel 32:32). Tuhan tidak menginginkan kematian manusia di dalam dosanya, melainkan pertobatannya dan menerima anugerah keselamatan dari Tuhan (Yeh 33:11). Tuhan akan menuntut pertanggungjawaban dari semua hamba Tuhan yang membiarkan orang berdosa mati di dalam dosanya (Yeh 3:18).

Hamba Tuhan Dipanggil untuk Siap Diutus, Kapan Saja, Kemana Saja, Dan Kepada Siapa Saja

\section{KEPUSTAKAAN}

Baxter, J. Sidlow

1981 Menggali Isi Alkitab. Jakarta: BPK Gunung Mulia.

Blommendaal, J.

1979 Pengantar Kepada Perjanjian Lama. Jakarta: BPK Gunung Mulia.

Boyd, Frank M.

1953 Kitab Nabi-nabi Kecil. Missouri: Gospel Publishing House.

Brown, Francis

1979 The Brown-Driver-Brigs-Gesenius Hebrew and English Lexicon. Massachusetts: Hendrickson Publishers.

Calvin, John 
1979 Commentaries on the Twelve Minor Prophets, vol. 2. Grand Rapids, Michigan: Baker Book House.

Douglas, J.D.

1995 Ensiklopedi Alkitab Masa Kini. Jakarta: Yayasan Komunikasi Bina Kasih/OMF

Green, Denis

1984 Pembimbing pada Pengenalan Perjanjian Lama. Malang: Gandum Mas.

Harris, R.Laird (ed)

1980 Theological Wordbook of the Old Testament, vol.1 \& 2. Chicago: Moody Press.

Henderson, Ebenezer

1981 Twelve Minor Prophets. Grand Rapids, Michigan: Baker Book House.

Hill, Andrew \& John H. Wilton

1996 Survey Perjanjian Lama. Malang: Gandum Mas.

Hubbard, David A. \& Glenn W. Barker (gen.ed.)

1987 Word Biblical Commentary, vol.31. Texas: Word Books Publishers.

Keil, C.F. \& F. Delitzsch

1985 Commentary on the Old Testament, vol. X. Grand Rapids, Michigan: WmB. Eerdmans Publishing Company.

Laetsch, Theo

1956 The Minor Prophets. Saint Louis, Missouri: Concordia Publishing House.

Owens, John Joseph

1992 Analytical Key to the Old Testament. Grand Rapids,

Walvoord, John F. Michigan: Baker Book House.

1985 The Bible Knowledge Commentary. Wheaton, Illinois: Victor Books.

Wiseman, D.J. (gen.ed.)

1997 Tyndale Old Testament Commentaries (Obadiah, Jonah, and Micah). England: Inter-varsity Press. 